\title{
Sulfonium Ion-Promoted Traceless Schmidt Reaction of Alkyl Azides
}

Received 00th January 20xx, Accepted 00th January 20xx

DOI: $10.1039 / x 0 x \times 00000 x$
Bayu Ardiansah, ${ }^{\mathrm{a}}$ Hiroki Tanimoto, ${ }^{* a, b}$ Takenori Tomohiro, ${ }^{\mathrm{b}}$ Tsumoru Morimoto, ${ }^{\mathrm{a}}$ and Kiyomi Kakiuchi ${ }^{\mathrm{a}}$
Schmidt reaction by sulfonium ions is described. General primary, secondary, and tertiary alkyl azides were converted to the corresponding carbonyl or imine compounds without any trace of the activators. This bond scission reaction showcased ring-opening, -expansion, and one-pot further conversion of the substrates.

Recent advances of functionalization by inactive bond cleavage have changed the synthetic planning of organic compounds. ${ }^{1}$ These versatile chemical reactions enable late-stage conversion of complex molecules, such as bioactive compounds into novel drug candidates with improved activity or functionalized chemical probe compounds. In this context, the azido group has also been known not only as a precursor of an amino group and as a molecular click conjugation scaffold in the chemical biology area, but also for its potent reactivity to lead ring-expansion, opening, or fragmentation of the molecules through disconnection of robust $\mathrm{C}-\mathrm{C}$ and inactive $\mathrm{C}-\mathrm{H}$ bonds (Figure 1A). ${ }^{2,3}$ Among the reactions of azides, the Schmidt (BoyerSchmidt) reaction is one of the well-known methods for robust bond cleavage and has been utilized in a wide range of synthetic organic chemistry (Figure 1B). ${ }^{4-6}$ Thus, organic azides, which are also available by recent late-stage azidation, ${ }^{7}$ could be potential scaffolds of molecular structural diversity through robust bond scission. However, because of the low nucleophilicity of organic azides, the Schmidt reaction usually requires carbon electrophiles (intramolecular in most cases) such as

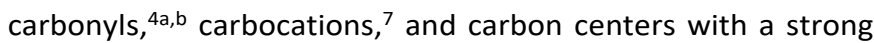
leaving group. ${ }^{6}$ Also, the need for carbon electrophiles forming new $\mathrm{C}-\mathrm{N}$ bonding may lead to unnecessary substitution onto the nitrogen atom or difficulty in substrate preparation. Although activation of azides at migration-accessible benzylic ${ }^{8}$ or carbonyl- $\alpha$-positions ${ }^{9,10}$ without carbon nucleophiles has been

\footnotetext{
aivision of Materials Science, Nara Institute of Science and Technology (NAIST), 8916-5 Takayama-cho, Ikoma, Nara 630-0192, Japan.

b. Graduate School of Medicine and Pharmaceutical Sciences, Toyama University, 2630 Sugitani, Toyama 930-0194, Japan.

E-mail: tanimoto@pha.u-toyama.ac.jp

+ Electronic Supplementary Information (ESI) available: Analytical data of the compounds and NMR study. CCDC 2083663
}

reported, that of general alkyl azides requires excess strong acids or high temperatures. ${ }^{11}$ With this background, C-H or C-C bond scission by activation of primary and secondary alkyl azides, $^{12,13}$ and geminal diazides ${ }^{14}$ has also been developed recently. Nevertheless, that of ubiquitous alkyl azides, especially tert-alkyl azides, is still difficult. ${ }^{13 d}$

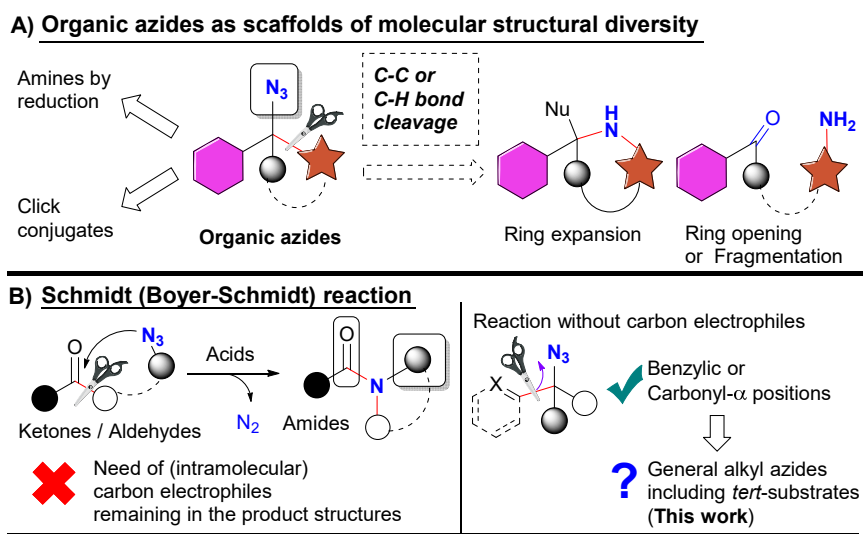

C) Traceless Schmidt reaction by sulfonium activator (this work)

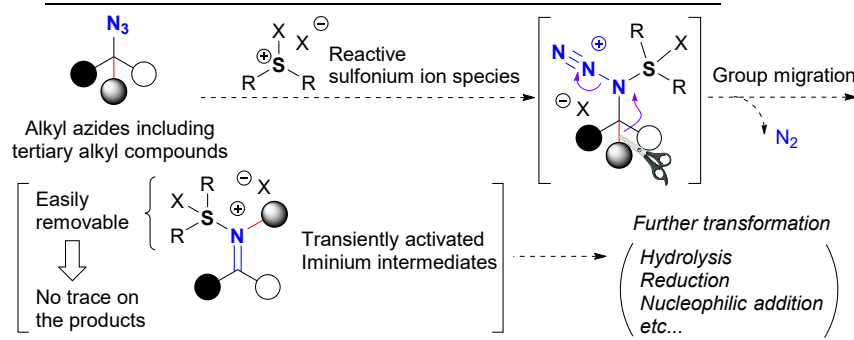

Figure 1. Organic azides as scaffolds of molecular diversity, and Schmidt reaction cleaving inert chemical bonding.

To overcome the difficulties above, we focused on reactive sulfonium ion species easily prepared from commercial sulfoxides. ${ }^{15}$ As demonstrated in Pummerer rearrangement, ${ }^{16}$ the reactive sulfonium ions are potent electrophiles. We envisaged these species as key activators of low-nucleophilic organic azides, which induce the migration of the substituent onto the nitrogen atom in the azido group with the elimination 
of molecular nitrogen (Figure $1 \mathrm{C}$ ). Compared to the general Schmidt reaction initially forming $\mathrm{C}-\mathrm{N}$ bond, ${ }^{4}$ it is advantageous that the formed $\mathrm{S}-\mathrm{N}$ bond could be easily disconnected after aqueous treatment. In addition, unlike borate-mediated reactions, ${ }^{4 c-e}$ the cationic sulfonium species could suppress the undesired migration of the $S$-substituents. We also anticipated that the use of sterically small sulfonium ions could approach bulky tert-alkyl azides to activate. Overall, the traceless Schmidt reaction of organic azides by sulfonium ion, namely interrupted Pummerer reaction ${ }^{16}$ with organic azides from the view of sulfoxide, should afford imines by chemical bond cleavage without the residue of the activators. It is also advantageous that the generated transiently activated imines would be capable of additional transformation reactions in one pot. Herein, we report our sulfonium ion-mediated traceless Schmidt reaction of primary, secondary, and tertiary alkyl azides.

Table 1. Optimization of Reaction Conditions

\begin{tabular}{|c|c|c|c|c|}
\hline \multicolumn{3}{|c|}{$\begin{array}{l}\text { Conditions } \\
\text { then } \\
\text { aqueous work up } \\
\text { (sat. } \mathrm{NaHCO}_{3} \text { aq.) }\end{array}$} & \multicolumn{2}{|c|}{$2 a$} \\
\hline Entry $^{a}$ & Sulfoxide & Activator & Solvent & Yield $(\%)^{b}$ \\
\hline 1 & - & $\mathrm{Tf}_{2} \mathrm{O}(2 \mathrm{eq})$ & $\mathrm{CH}_{2} \mathrm{Cl}_{2}$ & $0^{c}$ \\
\hline 2 & DMSO (2 eq) & $\mathrm{Tf}_{2} \mathrm{O}(2 \mathrm{eq})$ & $\mathrm{CH}_{2} \mathrm{Cl}_{2}$ & 14 \\
\hline 3 & DMSO (2 eq) & $\mathrm{Tf}_{2} \mathrm{O}(2 \mathrm{eq})$ & $\mathrm{CH}_{3} \mathrm{CN}$ & 10 \\
\hline 4 & DMSO (2 eq) & $\mathrm{Tf}_{2} \mathrm{O}(2 \mathrm{eq})$ & $\mathrm{CH}_{3} \mathrm{Ph}$ & 50 \\
\hline 5 & $\mathrm{Bn}_{2} \mathrm{~S}=\mathrm{O}(2 \mathrm{eq})$ & $\mathrm{Tf}_{2} \mathrm{O}(2 \mathrm{eq})$ & $\mathrm{CH}_{3} \mathrm{Ph}$ & 14 \\
\hline 6 & $\mathrm{Ph}_{2} \mathrm{~S}=\mathrm{O}(2 \mathrm{eq})$ & $\mathrm{Tf}_{2} \mathrm{O}(2 \mathrm{eq})$ & $\mathrm{CH}_{3} \mathrm{Ph}$ & 9 \\
\hline 7 & DMSO (2 eq) & $\mathrm{Tf}_{2} \mathrm{O}(4 \mathrm{eq})$ & $\mathrm{CH}_{3} \mathrm{Ph}$ & 64 \\
\hline 8 & DMSO (2 eq) & $\mathrm{Ts}_{2} \mathrm{O}(4 \mathrm{eq})$ & $\mathrm{CH}_{3} \mathrm{Ph}$ & 0 \\
\hline 9 & DMSO (2 eq) & $n-\mathrm{C}_{4} \mathrm{~F}_{9} \mathrm{SO}_{2} \mathrm{~F}$ (4 eq) & $\mathrm{CH}_{3} \mathrm{Ph}$ & 0 \\
\hline \multirow[t]{2}{*}{10} & \multirow[t]{2}{*}{ DMSO (2 eq) } & $\mathrm{Tf}_{2} \mathrm{O}(2 \mathrm{eq})$ & $t$-BuPh & $70(60)$ \\
\hline & & & & {$[65(61)]^{d}$} \\
\hline 11 & DMSO-d6 (2 eq) & $\mathrm{Tf}_{2} \mathrm{O}(2 \mathrm{eq})$ & $t-\mathrm{BuPh}$ & 63 \\
\hline 12 & DMSO (1.2 eq) & $\mathrm{Tf}_{2} \mathrm{O}(1.2 \mathrm{eq})$ & $t$-BuPh & 64 \\
\hline 13 & DMSO (0.5 eq) & $\mathrm{Tf}_{2} \mathrm{O}(0.5 \mathrm{eq})$ & $t$-BuPh & $24^{e}$ \\
\hline 14 & DMSO (2 eq) & $\mathrm{Tf}_{2} \mathrm{O}(2 \mathrm{eq})$ & $i-\mathrm{PrPh}$ & 50 \\
\hline 15 & DMSO (2 eq) & $\mathrm{Tf}_{2} \mathrm{O}(2 \mathrm{eq})$ & $\mathrm{CF}_{3} \mathrm{Ph}$ & 56 \\
\hline 16 & DMSO (2 eq) & $\mathrm{Tf}_{2} \mathrm{O}(2 \mathrm{eq})$ & $\mathrm{Cl}-\mathrm{Ph}$ & 36 \\
\hline
\end{tabular}

${ }^{a} 0.2 \mathrm{mmol}$ scale reactions. ${ }^{b}$ Yield based on ${ }^{1} \mathrm{H}$ NMR with internal standard 1,1,2,2tetrachloroethane (isolated yield in bracket). ${ }^{c 99 \%}\left({ }^{1} \mathrm{H} \mathrm{NMR}\right.$ ) of 1 a was recovered. ${ }^{d} 2.0$ mmol scale reaction. $f 57 \%$ of 1 a was recovered.

We commenced our research with 1 a as a non-benzylic primary alkyl azido substrate, and the conditions were investigated to serve aldehyde $\mathbf{2} \mathbf{a}$ after aqueous work-up (Table 1). The sole use of triflic anhydride did not work, but in-situ preparation of sulfonium species with DMSO gave $\mathbf{2 a}$ (entries $1-3$ ). We found that toluene served $\mathbf{2 a}$ in $50 \%$ yield (entry 4 ). Using other sulfoxides resulted in much lower yields, probably due to the steric hindrance compared to DMSO (entries 5,6). Excess use of triflic anhydride improved the yield (entry 7). Because of the nucleophilic halide or the lower leaving property, other activators did not give $\mathbf{2 a}$ (entries 8,9 ). After extensive research, tert-butylbenzene solvent served $\mathbf{2} \mathbf{a}$ in $70 \%$ yield and allowed in large scale (entry 10). The use of DMSO-d6 (entry 11) did not influence the results. Reducing the reagents also gave similar results despite slow reaction ( $2.5 \mathrm{~h}$ for entry $10 ; 5 \mathrm{~h}$ for entry 12), but the use in catalytic amount did not work (entry 13). Other similar benzene-type solvents also afforded $\mathbf{2 a}$, but in lower yields (entries 14-16).

To understand the reaction progress, we examined the NMR study of the reaction with 1 a (see ESI). Interestingly, after addition of triflic anhydride, no substrate-derived material other than trace 1a was found in the organic layer. On the other hand, from the insoluble layer generated after addition of triflic anhydride, organic components were observed. Aldehyde 2a was not observed at this point, but a broad signal at $8.47 \mathrm{ppm}$ to be assigned as $\mathrm{C}-\mathrm{H}$ of aldimine structure was found. After an aqueous quench of the reaction, $\mathbf{2 a}$ was generated. These observations could strongly suggest the presence of aldimine intermediate during the reaction before hydrolysis.

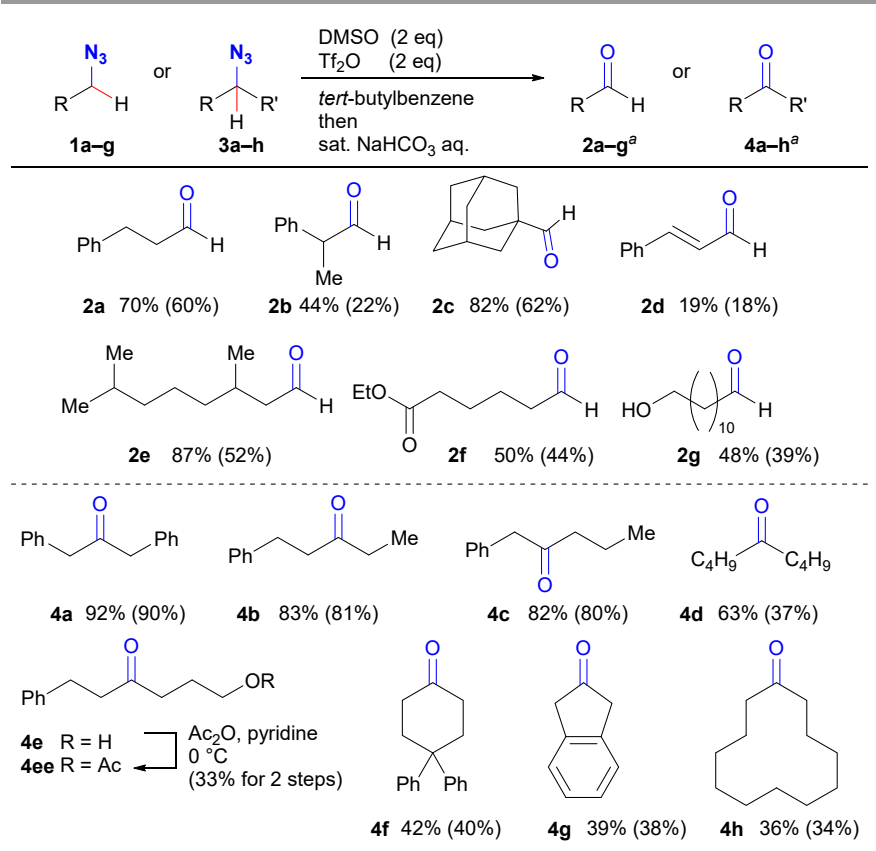

Scheme 1. Substrate scope of primary and secondary alkyl azides $(0.2 \mathrm{mmol}$ scale). a Yield based on ${ }^{1} \mathrm{H}$ NMR (isolated yield in bracket).

Having established the standard conditions, we next assessed the substrate scope of the primary and secondary alkyl azides (Scheme 1). For primary alkyl azides, the substitution degree of the adjacent position of the azido group did not influence the reactivity to afford the corresponding aldehydes $\mathbf{2 b}$ and $\mathbf{2 c}$ after aqueous treatment. The presence of the unsaturated bond reduced the product yield of $\mathbf{2} \mathbf{d}$ because the sulfonium ions also react with the olefins. ${ }^{17}$ The branched alkyl substrate $\mathbf{1 e}$ delivered $\mathbf{2} \mathbf{e}$ in good yield. The ester and hydroxy groups were tolerable to give $\mathbf{2 f}$ and $\mathbf{2 g}$. Indeed, 3phenylpropanol, a synthetic precursor of $1 \mathbf{a}$, did not afford the oxidized compound $2 \mathrm{2a}$ (93\% recovery yield based on ${ }^{1} \mathrm{H} N M R$ ).

Next, the secondary alkyl azides producing ketones were examined. Unlike the unstable aldehydes, acyclic azides $\mathbf{3 a - d}$ gave the corresponding ketones $\mathbf{4 a -} \mathbf{d}$ in moderate to excellent yields. Alcohol $3 e$ was also successfully converted to the unstable ketone product $4 \mathbf{e}$ which was isolated after acetylation to give $\mathbf{4 e e}$. The cyclic compounds $\mathbf{3 f}-\mathbf{h}$ were also sufficiently transformed into $\mathbf{4 f - h}$. 


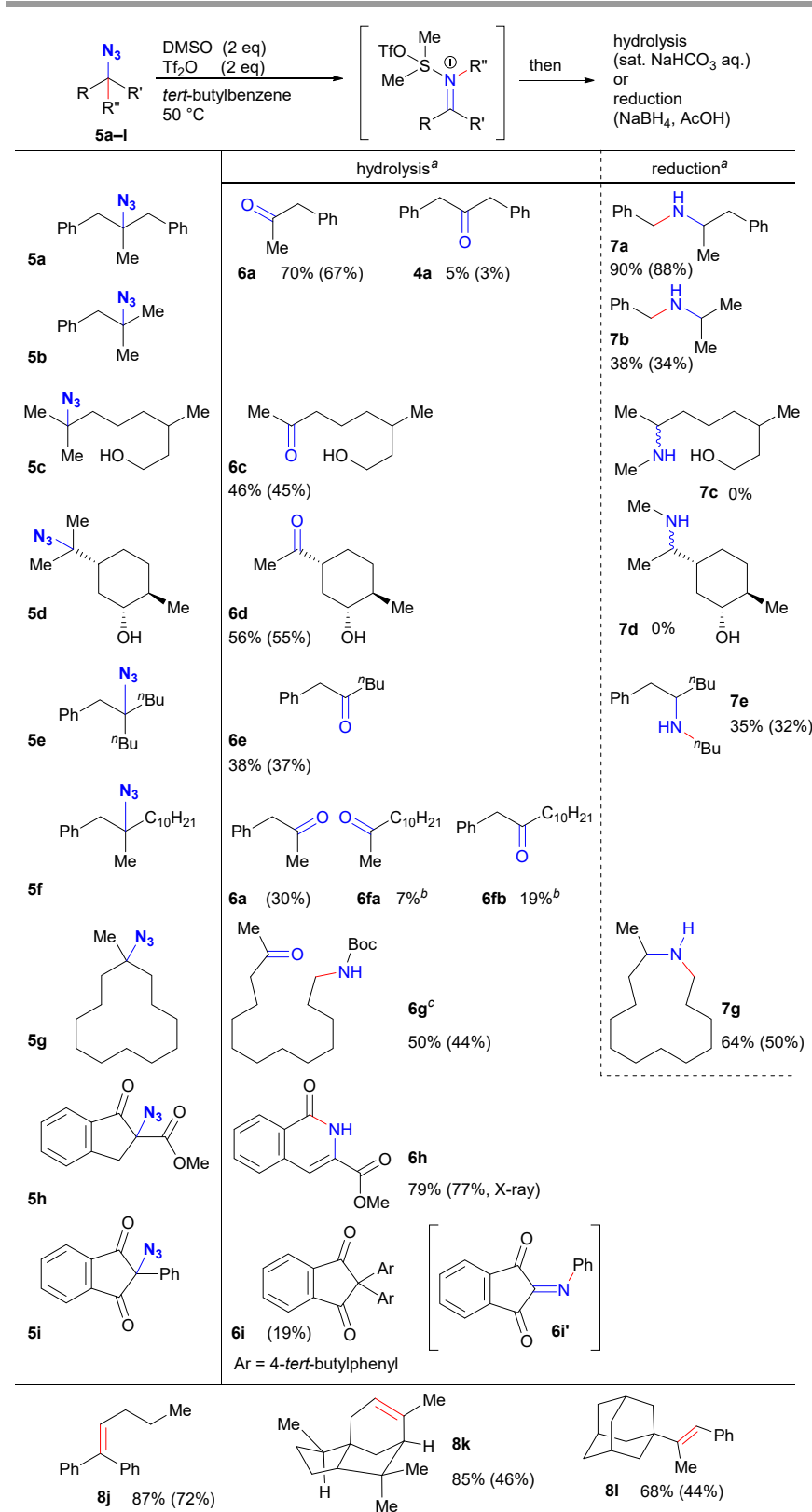

Scheme 2. Substrate scope of tert-alkyl azides on one-pot hydrolysis or reductive amination reaction $\left(0.2 \mathrm{mmol}\right.$ scale). ${ }^{a}$ Yield based on ${ }^{1} \mathrm{H}$ NMR (isolated yield in bracket). ${ }^{b} \mathrm{NMR}$ yields as an Inseparable mixture of $\mathbf{6} \mathbf{f a}$ and $\mathbf{6} \mathbf{f b}$. Isolated after hydrolysis followed by Boc protection $\left(\mathrm{Boc}_{2} \mathrm{O}, \mathrm{NaHCO}_{3}, \mathrm{H}_{2} \mathrm{O}, \mathrm{CH}_{2} \mathrm{Cl}_{2}\right.$ ).

Subsequently, we turned to the substrate scope of tertiary alkyl azides delivering carbon-carbon bond cleavages (Scheme 2). We examined both hydrolysis treatment to obtain fragmented compounds and one-pot reductive amination to give amino group-inserted products. tert-alkyl azide $5 \mathrm{a}$ with two benzyl and one methyl groups gave $\mathbf{6} \mathbf{a}$ by benzyl migration as a major product, associated with methyl-migrated 4 a in fair yield. Heating $5 a$ without reagents resulted in no reaction. Reductive amination gave $N$-benzyl amine 7 a in excellent yield, and this is proof of the presence of imine intermediate. Hydrolysis of $\mathbf{5 b}$ was not tested due to the volatility of the fragments, but the reductive amination successfully gave $\mathbf{7 b}$ in moderate yield. Interestingly, methyl groups in $\mathbf{5 c}$, $\mathbf{d}$ were removed to give $\mathbf{6 c , d}$, while the butyl group in $5 \mathbf{e}$ was migrated to obtain $6 \mathbf{e}$ and $7 \mathbf{e}$ even in the presence of benzyl group. Unfortunately, $N$-methyl compounds $\mathbf{7 c}, \mathbf{d}$ were not obtained, probably due to the $\mathrm{S}_{\mathrm{N}} 2$ type removal of the small methyl groups in the activated iminium intermediates. To check the order of the group migration, $\mathbf{5} \mathbf{f}$ possessing three different alkyl groups was tested. Interestingly, the major product was decyl-cleaved $\mathbf{6 a}$, and the benzyl-migrated ketone $\mathbf{6 f a}$ was the minor. From macrocyclic tert-alkyl azide $\mathbf{5 g}$, ring-opening reaction successfully gave difunctional acyclic amino ketone $\mathbf{6 g}$ after Boc protection. By reductive amination instead of hydrolysis, ring-expanded secondary amine $\mathbf{7 g}$ was obtained. The reaction with $\mathbf{5 h}$ of azide at carbonyl- $\alpha$-position delivered isoquinolinone $6 \mathbf{h}^{9 \mathrm{~d}}$ by ketone migration in good yield. 2-Azido-2-phenyl indandione $\mathbf{5 i}$ has been reported to give ring-expanded compound through carbonyl migration by heating at $180^{\circ} \mathrm{C}$ or photoirradiation. ${ }^{9 a, g, h}$ However, in contrast, our reaction condition afforded only 2,2diarylated $\mathbf{6 i}$ through migration of the phenyl group followed by double Friedel-Crafts reaction of ninhydrin imine $6 \mathbf{i}^{\prime}$ with the solvent molecules. ${ }^{18}$ As observed in the previous reports, ${ }^{4,5 b}$ these phenomena should represent the complexity of Schmidt reaction mechanism. Probably, both group characteristics and the conformations of the intermediates would influence the migration selectivity. We also faced elimination side reaction to give $\mathbf{5} \mathbf{j}-\mathbf{I}$ due to the generation of stable dibenzyl cation, steric hindrance and robust structure avoiding migration.

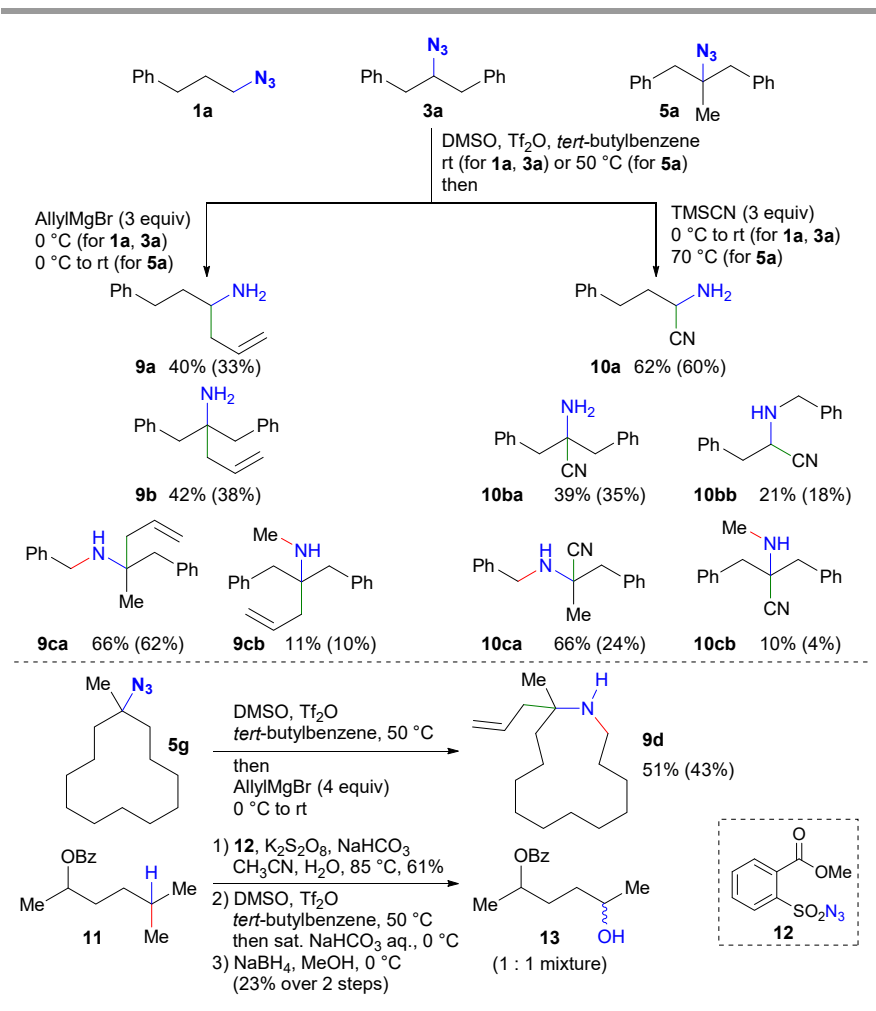

Scheme 3. One-pot functionalization of alkyl azides and conversion through $\mathrm{C}-\mathrm{H}$ and $\mathrm{C}-\mathrm{C}$ bond activation. Yield based on ${ }^{1} \mathrm{H}$ NMR (isolated yield in bracket).

Finally, we examined the one-pot functionalization of the imine intermediates with carbon nucleophiles (Scheme 4). With primary and secondary alkyl azides $\mathbf{1 a}$ and $\mathbf{3 a}$, the addition of Grignard reagent gave primary amines $\mathbf{9 a , b}$ as following the yields in Schemes 1 and 2. We also conducted Strecker reaction 
giving $\alpha$-amino acid precursor amino nitriles. ${ }^{19}$ As expected, unprotected amino nitriles 10a, 10ba, and 10bb were obtained by transient activation of the imines with the sulfonium group. The unexpected secondary amine $10 \mathrm{bb}$ would be obtained by intra- or intermolecular migration of the benzyl group in $10 \mathrm{ba}$ With tert-alkyl azides $\mathbf{5 a}$ and $\mathbf{5 g}$, the $\mathrm{N}$-substituted products possessing the tetrasubstituted carbon centres were afforded gratifyingly. Furthermore, the unfunctionalized alkyl chain in $\mathbf{1 1}$ was successfully modified through $\mathrm{C}-\mathrm{H}$ azidation ${ }^{7,20}$ with $\mathbf{1 2}^{21}$ followed by this traceless Schmidt reaction C-C bond cleavage.

In summary, we showcased the traceless Schmidt reaction of alkyl azides with sulfonium ion activator. General alkyl azides were successfully converted to the corresponding carbonyl or imine compounds through ring-opening, -expansion, or fragmentation, without any trace of the activators in the products. One-pot conversion and application with $\mathrm{C}-\mathrm{H}$ azidation enabled further functionalization of the conducted compounds. This method expands the utility of organic azides, which develop the diversity of the molecular structures.

This work was supported in part by the research grant from the NAIST foundation (31390000). We thank Ms. Yoshiko Nishikawa, Ms. Mieko Yamagaki (Mass Spectroscopy), and Mr. Shohei Katao (X-ray analysis) of NAIST.

\section{Conflicts of interest}

The authors declare no competing financial interest.

\section{Notes and references}

1 (a) F. Kakiuchi, and S. Murai, Acc. Chem. Res., 2002, 35, 826; (b) C-H Activation, eds. J.-Q. Yu and Z.-J. Shi, Springer, Berlin, Germany, 2010; (c) C-C Bond Activation, ed. G. Dong, Springer, 2014.

2 (a) Organic Azides, Syntheses and Applications, eds. S. Bräse and K. Banert, Wiley, Chichester, 2010; (b) H. Tanimoto and K. Kakiuchi, Nat. Prod. Commun., 2013, 8, 1021.

3 (a) H. C. Colb, M. G. Finn, and K. B. Sharpless, Angew. Chem. Int. Ed., 2001, 40, 2004; (b) C. W. Tornøe, C. Christensen, and M. Meldal, Chem. Rev., 2008, 108, 2952; (c) J. C. Jewetta and C. R. Bertozzi, Chem. Soc. Rev., 2010, 39, 1272.

4 (a) E. Nyfeler, P. Renaud, Chimia, 2006, 60, 276; (b) A. Wrobleski, T. C. Coombs, C. W. Huh, S.-W. Li, and J. Aubé, Org. React. 2012, 78, 1; for Schmidt-type reaction by intramolecular complexation with alkyl boranes, see (c) H. C. Brown, A. Suzuki, S. Sono, M. Itoh, and M. M. Midland, J. Am Chem. Soc. 1971, 93, 4329; (d) D. A. Evans and A. E. Weber, J. Am. Chem. Soc., 1987, 109, 7151; (e) F.-X. Felpin, S. Girard, G. Vo-Thanh, R. J. Robins, J. Villiéras, and J. Lebreton, J. Org. Chem., 2001, 66, 6305.

5 For $\mathrm{S}_{\mathrm{N}}$ 2-type Schmidt reaction, see: (a) A. Kapat, E. Nyfeler, G. T. Giuffredi, and P. Renaud, J. Am. Chem. Soc., 2009, 131 17746. (b) L. Gnägi, R. Arnold, F. Giornal, H. Jangra, A. Kapat, E. Nyfeler, R. M. Schärer, H. Zipse, and P. Renaud, Angew. Chem. Int. Ed., 2021, 60, 10179.

6 For our works on allyl cation-mediated Schmidt reactions, see (a) K. Hayashi, H. Tanimoto, H. Zhang, T. Morimoto, Y. Nishiyama, and K. Kakiuchi, Org. Lett., 2012, 14, 5728; (b) H. Zhang, K. Hayashi, H. Tanimoto, T. Morimoto, Y. Nishiyama, and K. Kakiuchi, Tetrahedron, 2014, 70, 8600; (c) T. Yokoi, T. Sugiura, H. Tanimoto, T. Morimoto, Y. Nishiyama, and K. Kakiuchi, Heterocycles, 2016, 92, 1313; with propargyl cation, see: (d) H. Zhang, H. Tanimoto, T. Morimoto, Y. Nishiyama, and K. Kakiuchi, Org. Lett., 2013, 15, 5222.

7 (a) P. Sivaguru, Y. Ning, X. Bi, Chem. Rev., 2021, 121, 4253; (b) L. Ge, M.-F. Chiou, Y. Li, and H. Bao, Green Synth. Catal., 2020, 1, 86; for recent works, see: (c) L. Niu, C. Jiang, Y. Liang, D. Liu, F. Bu, R. Shi, H. Chen, A. D. Chowdhury, and A. Lei, J. Am. Chem. Soc., 2020, 142, 17693; (d) T. H. Meyer, R. C. Samanta, A. Del Vecchio, and L. Ackermann, Chem. Sci., 2021, 12, 2890.

8 (a) K. Schildknegt, K. A. Agrios, and J. Aubé, Tetrahedron Lett. 1998, 39, 7687; (b) P. Desai, K. Schildknegt, K. A. Agrios, C. Mossman, G. L. Milligan, and J. Aubé, J. Am. Chem. Soc. 2000, 122, 7226; (c) A. Wrobleski and J. Aubé, J. Org. Chem., 2001, 66, 886; (d) J. He, K. Yamaguchi, N. Mizuno, J. Org. Chem. 2011, 76, 4606; (e) S. Giovani, R. Singh, and R. Fasan, Chem. Sci., 2016, 7, 234; (f) J. Liu, X. Qiu, X. Huang, X. Luo, C. Zhang, J. Wei, J. Pan, Y. Liang, Y. Zhu, Q. Qin, S. Song, and N. Jiao, Nat. Chem., 2019, 11, 71; (g) K. Wei, T. Yang, Q. Chen, S. Liang, and W. Yu, Chem. Commun., 2020, 56, 11685.

9 (a) H. W. Moore and D. S. Pearce, Tetrahedron Lett., 1971, 12, 1621; (b) D. S. Pearce, M. J. Locke, and H. W. Moore, J. Am. Chem. Soc., 1975, 97, 6181; (c) O. E. Edwards, J. L. Douglas, D. C. Howwell, W. Rank, and T. Sano, Can. J. Chem., 1992, 70, 2405; (d) T. Yang, X. Fan, X. Zhao, and W. Yu, Org. Lett., 2018, 20, 1875; (e) X. Zhao, S. Liang, X. Fan, T. Yang, and W. Yu, Org. Lett., 2019, 21, 1559; (f) T. Yang, Y. Lin, C. Yang, and W. Yu, Green Chem., 2019, 21, 6097; (g) U. Banerjee, S. K. Sarkar, J. A. Krause, W. L. Karney, M. Abe, and A. D. Gudmundsdottir, Org. Lett., 2020, 22, 7885; (h) F. Mittendorf, F. Mohr, and S. F. Kirsch, J. Org. Chem., 2020, 85, 12760.

10 (a) T. Yokoi, H. Tanimoto, T. Ueda, T. Morimoto, and K. Kakiuchi, J. Org. Chem., 2018, 83, 12103; (b) T. Yokoi, T. Ueda, H. Tanimoto, T. Morimoto, and K. Kakiuchi, Chem. Commun., 2019, 55, 1891.

11 (a) R. A. Abramovitch, E. P. Kyba, J. Am. Chem. Soc., 1974, 96, 480; (b) C. Wentrup, Chem. Rev., 2017, 117, 4562.

12 (a) G. Abbenante, G. T. Le, and D. P. Fairlie, Chem. Commun., 2007, 4501; (b) J. H. Lee, S. Gupta, W. Jeong, Y. H. Rhee, and J. Park, Angew. Chem. Int. Ed., 2012, 51, 10851; (c) Y. Kim, H. K. Pak, Y. H. Rhee, and J. Park, Chem. Commun., 2016, 52, 6549; (d) Y. Kwon, Y. H. Rhee, and J. Park, Adv. Synth. Catal., 2017, 359, 1503; (e) L. Hu, Y. A. Liu, and X. Liao, Sci. Adv., 2017, 3, e1700826.

13 For $\beta$-hydroxy azides, see: (a) R. Hernández, E. I. León, P. Moreno, C. Riesco-Fagundo, C., and E. Suárez, J. Org. Chem., 2004, 69, 8437; (b) Q.-H. Fan, N.-T. Ni, Q. Li, L.-H. Zhang, and X.-S. Ye, Org. Lett. 2006, 8, 1007; (c) S. Chiba, Y.-J. Xu, and Y.F. Wang, J. Am. Chem. Soc., 2009, 131, 12886; Lee, Rhee, Park et al. recently reported one successful example for tertalkyl azide. See: (d) J. M. Lee, D. Y. Bae, J. Y. Park, H. Y. Jo, E. Lee, Y. H. Rhee, and J. Park, Org. Lett., 2020, 22, 4608.

14 I. E. Celik and S. F. Kirsch, Eur. J. Org. Chem., 2021, 53.

15 D. Kaiser, I. Klose, R. Oost, J. Neuhaus, and N. Maulide, Chem. Rev., 2019, 119, 8701.

16 (a) L. H. S. Smith, S. C. Coote, H. F. Sneddon, and D. J. Procter, Angew. Chem. Int. Ed., 2010, 49, 5832; (b) H. Yorimitsu, Chem. Rec., 2017, 17, 1156; (c) D. Kaiser, I. Klose, R. Oost, J. Neuhaus, and N. Maulide, Chem. Rev., 2019, 119, 8701.

17 J. Matsuo, H. Yamanaka, A. Kawana, and T. Mukaiyama, Chem. Lett., 2003, 32, 392.

18 H. N. Song, M. R. Seong, J. S. Son, and J. N. Kim, Synth. Commun., 1998, 28, 1865.

19 V. V. Kouznetsov, C. E. P. Galvis, Tetrahedron, 2018, 74, 773.

20 X. Zhang, H. Yang, and P. Tang, Org. Lett., 2015, 17, 5828.

21 J. Waser, B. Gaspar, H. Nambu, and E. M. Carreira, J. Am. Chem. Soc., 2006, 128, 11693. 